\title{
Structure modification of a milk protein-based model food affects postprandial intestinal peptide release and fullness in healthy young men
}

\author{
Kristiina R. Juvonen ${ }^{1}$, Leila J. Karhunen ${ }^{1}$, Elisa Vuori ${ }^{2}$, Martina E. Lille ${ }^{3}$, Toni Karhu ${ }^{2}$, \\ Alicia Jurado-Acosta ${ }^{2}$, David E. Laaksonen ${ }^{4,5}$, Hannu M. Mykkänen ${ }^{1}$, Leo K. Niskanen ${ }^{4}$, \\ Kaisa S. Poutanen ${ }^{1,3}$ and Karl-Heinz Herzig ${ }^{2,6_{*}}$ \\ ${ }^{1}$ Department of Clinical Nutrition, Institute of Public Health and Clinical Nutrition, Food and Health Research Centre, \\ University of Eastern Finland, 70211 Kuopio, Finland \\ ${ }^{2}$ Division of Physiology, Institute of Biomedicine, and Biocenter of Oulu, Oulu University, 90014 Oulu, Finland \\ ${ }^{3}$ VTT Technical Research Centre of Finland, O2150 Espoo, Finland \\ ${ }^{4}$ Department of Medicine, Kuopio University Hospital, 70211 Kuopio, Finland \\ ${ }^{5}$ Institute of Biomedicine, Physiology, University of Eastern Finland, 70211 Kuopio, Finland \\ ${ }^{6}$ Department of Psychiatry, Kuopio University Hospital, 70211 Kuopio, Finland
}

(Received 24 November 2010 - Revised 5 April 2011 - Accepted 5 April 2011 - First published online 21 June 2011)

\begin{abstract}
Physico-chemical and textural properties of foods in addition to their chemical composition modify postprandial metabolism and signals from the gastrointestinal tract. Enzymatic cross-linking of protein is a tool to modify food texture and structure without changing nutritional composition. We investigated the effects of structure modification of a milk protein-based model food and the type of milk protein used on postprandial hormonal, metabolic and appetitive responses. Healthy males $(n 8)$ consumed an isoenergetic and isovolumic test product containing either whey protein (Wh, low-viscous liquid), casein (Cas, high-viscous liquid) or Cas protein cross-linked with transglutaminase (Cas-TG, rigid gel) in a randomised order. Blood samples were drawn for plasma glucose, insulin, cholecystokinin (CCK), glucagonlike peptide 1 and peptide YY analysis for $4 \mathrm{~h}$. Appetite was assessed at concomitant time points. Cas and Wh were more potent in lowering postprandial glucose than Cas-TG during the first hour. Insulin concentrations peaked at 30 min, but the peaks were more pronounced for Cas and Wh than for Cas-TG. The increase in CCK was similar for Cas and Wh in the first 15 min, whereas for Cas-TG, the CCK release was significantly lower, but more sustained. The feeling of fullness was stronger after the consumption of Cas-TG than after the consumption of Cas and Wh. The present results suggest that food structure is more effective in modulating the postprandial responses than the type of dairy protein used. Modification of protein-based food structure could thus offer a possible tool for lowering postprandial glucose and insulin concentrations and enhancing postprandial fullness.
\end{abstract}

Key words: Casein: Whey protein: Cross-linking: Gastrointestinal peptides: Satiety

Dietary protein has recently attracted considerable attention in appetite control. Several studies have shown that protein is more satiating than other macronutrients ${ }^{(1-3)}$, possibly due to increased postprandial thermic effects, altered gastrointestinal (GI) functions and postprandial metabolism, e.g. increased amino acid (AA) concentration and gluconeogenesis ${ }^{(4)}$. Previous evidence ${ }^{(5)}$ also indicates the increased release of GI hormones, such as cholecystokinin (CCK), glucagon-like peptide 1 (GLP-1) and peptide YY (PYY) in response to protein intake.

As an analogy with dietary carbohydrates, Boirie et al. ${ }^{(6)}$ proposed the concept of 'fast' and 'slow' dairy proteins, which has been recently supported by other groups ${ }^{(7,8)}$. Between the two main milk protein fractions, whey protein (Wh) has been considered as a 'fast' digestible protein with soluble characteristics and a high and rapid AA profile, whereas casein (Cas) has been characterised as a 'slow' protein that precipitates in the stomach, leading to delayed gastric emptying (GE) and slower and lower AA levels. In addition, Cas and Wh have been shown to differentially affect postprandial GI hormone secretion and sensations of appetite ${ }^{(7)}$.

Foods and their components possess complex structural and textural characteristics that have been shown to influence

Abbreviations: AA, amino acid; Cas, casein; Cas-TG, casein cross-linked by transglutaminase; CCK, cholecystokinin; GE, gastric emptying; GI, gastrointestinal; GLP-1, glucagon-like peptide 1; PYY, peptide YY; TG, transglutaminase; Wh, whey protein. 
postprandial GI function and metabolism ${ }^{(9-12)}$. In general, viscous and solid food matrix and food characteristics resistant to post-ingestive digestion have been shown to delay GE and the subsequent absorption of nutrients in the upper GI tract $^{(11-13)}$. Previous studies have also shown that food texture and structure modulates the postprandial release of GI hormones $^{(10,12-15)}$ and may concomitantly affect sensations of appetite ${ }^{(15-19)}$. Furthermore, recent data demonstrate the importance of orosensory stimulation and oral processing time regarding different food characteristics, which may subsequently influence appetite sensations and food intake ${ }^{(20-22)}$. However, a controversy prevails over the effects of the physical form of foods and macronutrients on postprandial physiology, which warrants further clarification ${ }^{(23)}$.

Cross-linking enzymes (e.g. transglutaminase, TG) provide an ideal tool for proteinaceous matrices to create food structures and textures with desirable mechanical and sensory properties $^{(24,25)}$. Enzymatic cross-linking changes the complex food protein network, affecting the functional characteristics of proteins and protein-containing foods ${ }^{(24,26-28)}$. Based on current knowledge, cross-linking treatment does not, however, diminish the bioavailability and biological value of the cross-linked proteins since they can still be digested, absorbed and utilised in the body ${ }^{(29)}$. Despite the considerable amount of literature on the effects of cross-linking on food structure and texture, in vivo experiments to investigate their effects on postprandial physiology are very limited.

The objective of the present study was to investigate the effect of the type and structure of milk-protein based model foods on postprandial hormonal, metabolic and appetitive responses in healthy young males. The cross-linking enzyme TG was used as a tool to create two Cas-based test products of identical composition but with a difference in rheological properties (liquid $v$, gel).

Our hypothesis was that a more solid structure would promote satiety and attenuate postprandial GI peptide responses.

\section{Methods}

\section{Subjects}

Healthy male volunteers ( $n$ 8; Table 1 ) participated in the study at the Department of Physiology at Oulu University, Finland. The volunteers were recruited via advertisements posted across the campuses of Oulu University. A total of twelve volunteers were recruited to the study, of which eight individuals finished the study protocol including

Table 1. Participants' characteristics

(Mean values with their standard errors, $n 8$ )

\begin{tabular}{lrl}
\hline Characteristics & Mean & SEM \\
\hline Age (years) & 24.0 & 0.82 \\
Height $(\mathrm{m})$ & 1.8 & 0.02 \\
Weight $(\mathrm{kg})$ & 76.8 & 2.4 \\
BMI $\left(\mathrm{kg} / \mathrm{m}^{2}\right)$ & 23.3 & 0.5 \\
\hline
\end{tabular}

three subsequent visits. All volunteers were interviewed about their medical history, dietary habits and physical activity before the beginning of the study. Individuals with food intolerances or allergies, who were smokers, who had modified their diet or exercise routines during the past year to lose weight, or who were on medication were excluded.

The present study was conducted according to the guidelines laid down in the Declaration of Helsinki and all procedures involving human subjects were approved by the Ethics Committee of the University of Kuopio and Kuopio University Hospital. Written informed consent was obtained from all subjects.

\section{Study design}

The study had a randomised, repeated-measures, cross-over design. All participants tested each test product, with a minimum of $2 \mathrm{~d}$ separating the individual test days. The participants were requested to maintain their habitual diet and exercise routines throughout the study period.

After a $12 \mathrm{~h}$ fast, the participants ingested one of the following milk protein-based test products along with $400 \mathrm{ml}$ of water in a randomised order: (1) high-viscous Cas solution (Cas), (2) rigid Cas gel (Cas cross-linked by TG; Cas-TG), (3) low-viscous Wh solution (Wh). The test products were to be consumed within $30 \mathrm{~min}$.

Blood samples for the determination of plasma glucose, insulin, CCK, GLP-1 and PYY concentrations were taken via an antecubital cannula inserted before the start of the experiment. The blood samples were drawn before and at $15,30,60,120,180$ and $240 \mathrm{~min}$ following the ingestion of the test products.

\section{Test products}

A total of three isoenergetic and isovolumic milk proteinbased pH-neutral model foods were served as test products. The detailed composition of the products and ingredients used are shown in Tables 2 and 3, respectively.

The preparation of the Cas-based test products was performed as follows: protein powder was mixed in a bowl with boiling water under continuous stirring until a smooth solution was formed. The solution was allowed to cool down to room temperature before the addition of TG, which was suspended in a small amount of water. For the Cas test product, TG was inactivated by boiling the suspension for 5 min before adding it to the Cas solution. After the addition of the TG suspension, sweetener, aroma and water were added to each product to a final weight of $400 \mathrm{~g}$. The mixture was stirred for $1 \mathrm{~h}$ at room temperature and thereafter stored at $5^{\circ} \mathrm{C}$ for $14 \mathrm{~h}$, during which gelation took place in the product where TG was active (Cas-TG). The test products were served immediately after the $14 \mathrm{~h}$ storage time.

The preparation of the Wh-based product followed the procedure used with Cas, except that the added water was boiled and cooled down before mixing with the whey 
Table 2. Composition of the test products ${ }^{*}$

\begin{tabular}{lccc}
\hline & Cas & Cas-TG & Wh \\
\hline Portion size (g) & 400 & 400 & 400 \\
Energy (kJ (kcal)) & $976(230)$ & $976(230)$ & $950(223)$ \\
Energy density (kJ/g) & 2.4 & 2.4 & 2.4 \\
Protein (wt\% (\% energy)) & $13.2(91.7)$ & $13.2(91.7)$ & $12.9(92.2)$ \\
Carbohydrates (wt\% (\% energy)) & $0.9(6.5)$ & $0.9(6.5)$ & $1.0(6.9)$ \\
Fat (wt\% (\% energy)) & $0.12(1.8)$ & $0.12(1.8)$ & $0.05(0.8)$ \\
\hline
\end{tabular}

Cas, casein; Cas-TG, transglutaminase-treated Cas; Wh, whey protein.

* Ingested with $400 \mathrm{ml}$ of water.

powder to avoid heat-induced denaturation of Wh. Inactivated TG was added to the Wh product as well.

The texture of the test products was measured instrumentally with a Texture Analyser device (TA-HDi; Stable Micro Systems Limited, Godalming, UK) equipped with a $5 \mathrm{~kg}$ load cell. After all the ingredients were mixed with each other as described earlier, small plastic containers (inner diameter $42 \mathrm{~mm}$ ) were filled up to $50 \mathrm{ml}$ with test liquid (sample height approximately $35 \mathrm{~mm}$ ). The containers were closed with caps and $1 \mathrm{~h}$ after the TG addition transferred to a refrigerator $\left(5^{\circ} \mathrm{C}\right)$. The texture of the test products was measured after $14 \mathrm{~h}$ cold storage by recording the force required to push a $12.7 \mathrm{~mm}$ diameter hemispherical Delrin cylinder probe into the test product with a speed of $1 \mathrm{~mm} / \mathrm{s}$. The force at a depth of $15 \mathrm{~mm}$ was taken as a measure of sample firmness. At least five samples were measured for each test product. Wh was a low-viscous fluid (comparable to, for example, water or skimmed milk), Cas a high-viscous fluid with some elasticity (comparable to, for example, regular yogurt) and Cas-TG a very strong elastic gel (comparable to, for example, thick marmalade). The puncture test showed that the firmness of the Cas-TG product was very much higher than that of Cas or Wh (Fig. 1(A))

Table 3. Ingredients used in the test products ( $\mathrm{g} /$ portion)

\begin{tabular}{lccc}
\hline & Cas & Cas-TG & Wh \\
\hline Protein powder $(\mathrm{g})$ & $58.45^{\star}$ & $58.45^{\star}$ & $55.40 \dagger$ \\
Transglutaminase powder $(\mathrm{g}) \ddagger$ & 3.85 & 3.85 & 3.85 \\
Aroma $(\mathrm{g}) \S$ & 1.25 & 1.25 & 1.25 \\
Artificial sweetener $(\mathrm{g}) \|$ & 1.75 & 1.75 & 1.75 \\
Water up to 400 $\mathrm{g}$ & & & \\
\hline
\end{tabular}

Cas, casein; Cas-TG, transglutaminase-treated Cas; Wh, whey protein.

* Sodium caseinate EM7, (mainly Cas, proportion of individual caseins similar to that in milk), composition: $90 \%$ protein, $5 \%$ moisture, $4 \%$ ash, $0.8 \%$ fat and $0.2 \%$ lactose (DMV International, Veghel, The Netherlands).

† Wh isolate (mainly $\beta$-lactoglobulin), BiPRO ${ }^{8}$, composition: $92.9 \%$ protein, $5 \%$ moisture, $1.9 \%$ ash, $0.4 \%$ fat and $0.5 \%$ lactose (Davisco Foods International Incorporation, MN, USA).

‡ Transglutaminase powder, Activa MP, Ajinomoto Foods Deutschland $\mathrm{GmbH}$, Hamburg, Germany, activity 78-126 EU according to the manufacturer, composition: $94 \%$ carbohydrates, $5 \%$ moisture and $1 \%$ protein

$\S$ Vanilla aroma, Iberchem, Murcia, Spain.

\| Hermesetas Liquid, Hermes Sweeteners Limited, Zurich, Switzerland.

\section{Viscosity of whey protein and casein}

The viscosity of the liquid-like test products Wh and Cas was measured at $29^{\circ} \mathrm{C}$ with a stress-controlled rotational rheometer (AR-G2; TA Instruments, Crawley, West Sussex, UK) equipped with a four-bladed vane geometry. The diameter of the cylindrical sample cup was $30 \mathrm{~mm}$ and that of the vane $28 \mathrm{~mm}$. The length of the vane was $42 \mathrm{~mm}$. About $40 \mathrm{ml}$ of the sample were poured into the measuring cup and the vane was lowered into it so that the blades were just immersed. After positioning the vane, the samples were allowed to rest for $5 \mathrm{~min}$ before the measurement was started. The steady-state viscosity was measured with a gradually increasing shear stress with values resulting in shear rates in the range $0 \cdot 1-150 / \mathrm{s}$. The viscosity was presented as a function of shear rate (Fig. 1(B)). The viscosity of the syrup resembling Cas was very much higher than the viscosity of Wh (Fig. 1(B)), which was almost the same as water.

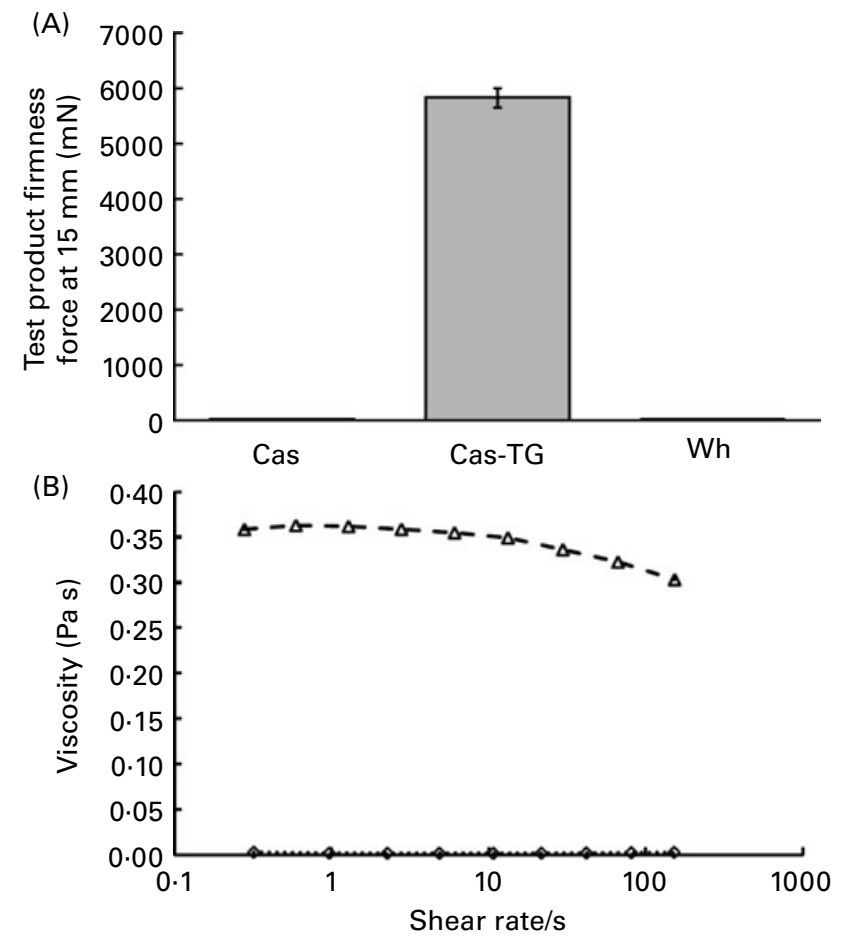

Fig. 1. (A) Firmness of the test products as measured by a puncture test using the Texture Analyser: casein (Cas, $-\Delta-$ ), transglutaminase-treated Cas (Cas-TG, $-\mathbf{-}-)$ ) and whey protein (Wh, ..॰..). Values are means, with standard errors represented by vertical bars. (B) Comparison of the viscosity of Cas $(-\triangle-)$ and Wh $(. \cdot \diamond \cdot \cdot)$. 


\section{Appetite measurements}

Participants rated their appetite immediately after each blood sample was drawn. In addition, pleasantness of the test products was rated before and immediately after the consumption of the test products. Profiles of appetite (hunger, satiety, desire to eat, fullness and thirst) and pleasantness of the test products were measured using visual analogue scales $^{(30)}$. Each scale consisted of a $100 \mathrm{~mm}$ horizontal line with verbal anchors expressing the weakest or strongest statement (i.e. 'I am not hungry at all' or 'I have never been hungrier'). The participants were requested to mark a vertical line on the horizontal axis corresponding to their sensations that were most appropriate at the time. Visual analogue scale ratings were measured in $\mathrm{mm}$, resulting in scores between 0 and 100 .

\section{Biochemical measurements}

Immediately after the blood samples were taken, $50 \mu \mathrm{l}$ of the protease dipeptidyl peptidase IV inhibitor (DPP IV Inhibitor; Millipore, West Sussex, UK) were added to the sample tubes to prevent the degradation of native GLP-1 by inhibiting the activity of the dipeptidyl peptidase IV enzyme.

Prechilled EDTA and trasylol $(250 \mathrm{KIU} / 5 \mathrm{ml})$ containing tubes were used for plasma insulin, CCK, GLP-1 and PYY, and fluoride citrate-containing tubes for plasma glucose. Plasma glucose, insulin, CCK, GLP-1 and PYY samples were centrifuged for $10 \mathrm{~min}$ at $1700 \mathrm{~g}$ at $4^{\circ} \mathrm{C}$. All samples were immediately frozen and stored at $-70^{\circ} \mathrm{C}$ until analysed. All the samples of each individual were analysed in duplicate and within the same assay. Results were obtained from all the study participants except for plasma GLP-1 measurements where six participants were included.

Plasma glucose was analysed using an enzymatic photometric assay (Thermo Electron Corporation, Vantaa, Finland) and plasma insulin with a luminometric immunoassay (Siemens Medical Solutions Diagnostics, Tarrytown, NY, USA). The intra-assay CV for plasma glucose was $2.7 \%$ at $10 \cdot 2 \mathrm{mmol} / \mathrm{l}$ and the inter-assay $\mathrm{CV}$ was $4.1 \%$ at $2.05 \mathrm{mmol} / \mathrm{l}$ and $1.8 \%$ at $8.2 \mathrm{mmol} / \mathrm{l}$. For plasma insulin, the intra-assay $\mathrm{CV}$ was $2.7 \%$ at $667 \mathrm{pmol} / 1$ and the inter-assay $\mathrm{CV}$ was $6.6 \%$ at $41 \mathrm{pmol} / 1$ and $5 \cdot 1 \%$ at $444 \mathrm{pmol} / \mathrm{l}$. Total plasma PYY, i.e. both $\mathrm{PYY}_{1-36}$ and $\mathrm{PYY}_{3-36}$, and active plasma GLP-1, i.e. GLP-1 $1_{7-36}$ amide and GLP-1 $1_{7-37}$, concentrations were quantified in a direct assay with the use of a Human Gut Hormone Panel Milliplex kit (Millipore, St Charles, MO, USA) utilising a Bio-Plex instrument based on Luminex xMAP technology (Bio-Rad Laboratories, Incorporation, CA, USA). The intraassay CV for the total GLP-1 was $10 \cdot 8 \%$ at $40 \cdot 1 \mathrm{pg} / \mathrm{ml}$ and $10.6 \%$ at $84.9 \mathrm{pg} / \mathrm{ml}$ and the inter-assay $\mathrm{CV}$ was $28.9 \%$ at $26 \mathrm{pg} / \mathrm{ml}$ and $15.8 \%$ at $202 \mathrm{pg} / \mathrm{ml}$. For the total PYY, the intra-assay CV was $4.1 \%$ at $78 \mathrm{pg} / \mathrm{ml}$ and $2.3 \%$ at $141.3 \mathrm{pg} / \mathrm{ml}$ and the inter-assay CV was $13.1 \%$ at $74.5 \mathrm{pg} / \mathrm{ml}$ and $12.2 \%$ at $164 \cdot 1 \mathrm{pg} / \mathrm{ml}$.

Plasma CCK concentrations were analysed after extraction using a RIA kit (Euro-Diagnostica AB, Malmö, Sweden). The plasma samples were extracted with a SepPac C18 cartridge preconditioned with $1.5 \mathrm{ml}$ of 2-propanol and $1.5 \mathrm{ml}$ of $0.1 \%$ trifluoroacetic acid (Waters, Milford, MA, USA) in an automated Gilson Aspec XL system (Gilson, Middleton, WI, USA). Then, $1 \mathrm{ml}$ of the plasma samples was acidified with $0.2 \mathrm{ml}$ of $1 \mathrm{M}-\mathrm{HCl}$ containing $1.6 \%$ glycine. After loading the sample, the cartridge was washed with $2 \mathrm{ml}$ of $0.1 \%$ trifluoroacetic acid, and the samples were eluted with $2 \mathrm{ml}$ of $80 \%$ acetonitrile in $0 \cdot 1 \%$ trifluoroacetic acid. The samples were evaporated into dryness overnight. The dry residue was dissolved in $500 \mu \mathrm{l}$ of RIA buffer and RIA was conducted according to the manufacturer's instructions. Briefly, the samples were incubated with the primary antibody for $48 \mathrm{~h}$ at $4^{\circ} \mathrm{C}$ and I-125-labelled CCK- 8 was added before $96 \mathrm{~h}$ incubation at $4^{\circ} \mathrm{C}$. A double-antibody solid phase was added and the samples were incubated for $60 \mathrm{~min}$ at $4^{\circ} \mathrm{C}$. Before the measurement, the samples were centrifuged for $15 \mathrm{~min}$ at $1700 \mathrm{~g}$ at $4^{\circ} \mathrm{C}$. The supernatant was decanted and the activity of aliquot was measured with a gammacounter (Wallac 1272 Clinigamma; Perkin-Elmer, Waltham, MA, USA). The intraassay CV for CCK was $5.5 \%$ at $4.4 \mathrm{pmol} / 1$ and $2.0 \%$ at $20.6 \mathrm{pmol} / 1$ and the inter-assay $\mathrm{CV}$ was $13.7 \%$ at $4.2 \mathrm{pmol} / 1$ and $4.1 \%$ at $20.6 \mathrm{pmol} / 1$.

\section{Statistical analysis}

Data analyses were performed with SPSS for Windows software (SPSS for Windows, version 17.0; SPSS Inc., Chicago, IL, USA). Results are expressed as means and standard errors of the mean with a value $P \leq 0.05$ (two-sided) as the criterion for statistical significance.

Linear mixed-effects modelling was used to compare the effects of the test products on the postprandial metabolic and hormonal responses and appetite sensations. The results have been analysed and are expressed based on the raw outcome values. The baseline value of each parameter was used as a covariate to take into account the possible effect of baseline differences on the analysis. The method takes into account the sources of variation, where the participant is used as a random factor and product, time and product $\times$ time as fixed factors. Where a significant main effect of a product, time or product $\times$ time interaction was observed $(P<0.05)$, post hoc analyses were performed using the Bonferroni correction for multiple comparisons to identify the significant differences among the test products at each time point of measurement.

\section{Results}

Mean time of test product consumption

The mean time for the consumption of the test products was $20 \cdot 3$ (SEM 2.9) $\mathrm{min}$ for Cas-TG, $6 \cdot 0$ (SEM 1.2) min for Cas and 2.5 (SEM 0.7 ) $\mathrm{min}$ for Wh.

\section{Plasma glucose and insulin responses}

Postprandial plasma glucose and insulin concentrations were significantly different following ingestion of the test products 
$(P<0.05$; Fig. 2(A) and (B)). After the ingestion of all test products, the concentration of plasma glucose slightly increased for $15 \mathrm{~min}$, declining thereafter and returning towards the preprandial concentrations after $60 \mathrm{~min}$. The postprandial insulin responses increased after the consumption of all test products and peaked at $30 \mathrm{~min}$ after which the concentration returned towards the baseline. Plasma insulin was higher at $15 \mathrm{~min}$ after the consumption of $\mathrm{Wh}$ and at $30 \mathrm{~min}$ after the consumption of Cas and Wh than after the consumption of Cas-TG $(P<0 \cdot 05)$. On the contrary, the decrease in plasma glucose at 30 and $60 \mathrm{~min}$ was greater after the consumption of Cas and Wh than after the consumption of Cas-TG $(P<0 \cdot 05)$.

\section{Plasma cholecystokinin, glucagon-like peptide 1 and peptide $Y Y$ responses}

Postprandial concentrations of plasma CCK peaked at $15 \mathrm{~min}$ and GLP-1 at $30 \mathrm{~min}$ after the consumption of all test products, after which the concentrations returned towards the baseline values (Fig. 2(C) and (D)). At the same time, postprandial PYY concentrations varied only slightly from the baseline values (about $90 \mathrm{pg} / \mathrm{ml}$, data not shown) during the experimental period. The test products resulted in significant differences in plasma CCK $(P<0.05)$, but not in plasma PYY $(P>0.05)$ concentration. CCK concentrations were increased after the consumption of Cas and Wh at $15 \mathrm{~min}$ compared with Cas-TG $(P<0 \cdot 001)$. Furthermore, at $30 \mathrm{~min}$, the CCK
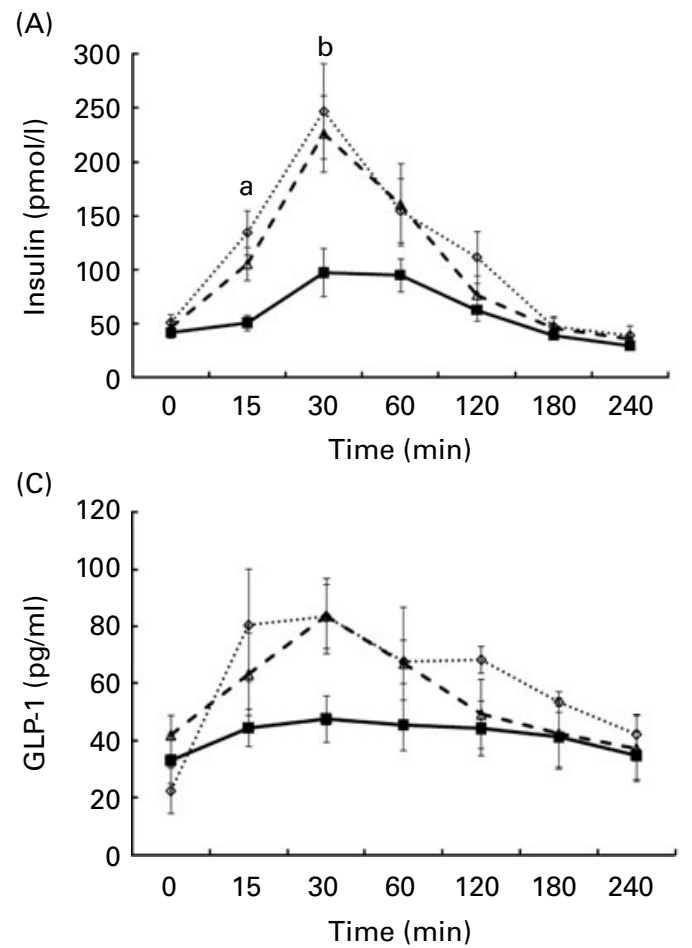

concentration was higher after the consumption of Cas than after the consumption of Cas-TG or whey products $(P<0.05)$. A trend $(P=0.074)$ was observed in GLP-1 responses among the test products such that GLP-1 concentration was increased after the consumption of Wh at $15 \mathrm{~min}$ and after the consumption of Cas at 30 min when compared with Cas-TG.

\section{Appetite ratings}

Ratings on estimated pleasantness differed before and after the consumption of the products $(P<0 \cdot 05)$. Mean pleasantness ratings immediately before (Cas-TG 21, Cas 33 and Wh 41) and after (Cas-TG 3, Cas 45 and Wh 67) the ingestion of the test products indicated that Cas-TG was rated least pleasant followed by Cas and Wh, respectively.

Ratings for hunger, satiety, desire to eat, fullness and thirst varied significantly with time $(P<0 \cdot 001 ;$ Fig. 3). Ratings of hunger, desire to eat and thirst initially decreased after the consumption of all test products, after which ratings returned gradually towards the baseline after $60 \mathrm{~min}$ at the latest. Measures of satiety and fullness increased after the ingestion of each product, reached peak values by $60 \mathrm{~min}$ and declined thereafter. Moreover, significant differences in fullness ratings were detected among the test products: fullness was markedly increased after the consumption of Cas-TG at 15, 30 and $120 \mathrm{~min}$ when compared with Wh and at $30 \mathrm{~min}$ when compared with Cas (Fig. 3(D)).
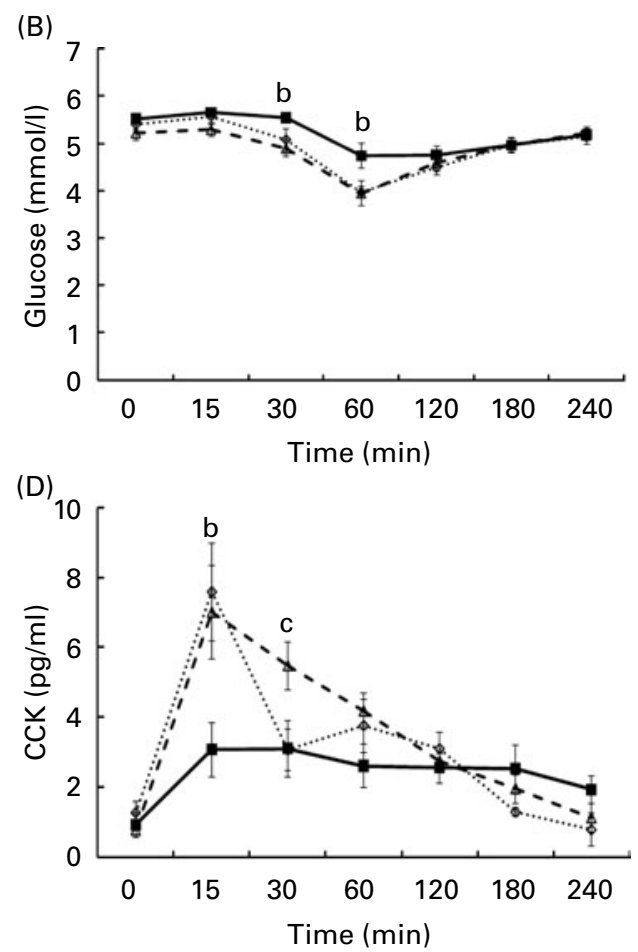

Fig. 2. Changes in the concentrations of plasma (A) insulin, (B) glucose, (C) glucagon-like peptide 1 (GLP-1) and (D) cholecystokinin (CCK) during the 240 min postprandial period in young men consuming casein (Cas, $-\Delta-$ ), transglutaminase-treated Cas (Cas-TG, $-\mathbf{\square}-$ ) or whey protein (Wh, .. $\diamond .$.$) test products.$ Values are means, with their standard errors represented by vertical bars ( $n$ 8, except for GLP-1 $n$ 6; linear mixed-effects modelling with Bonferroni correction). a,b,c Mean values with unlike letters were significantly different between Wh and Cas-TG, between Wh/Cas and Cas-TG and between Cas and Wh/Cas-TG $(P<0.05)$. 

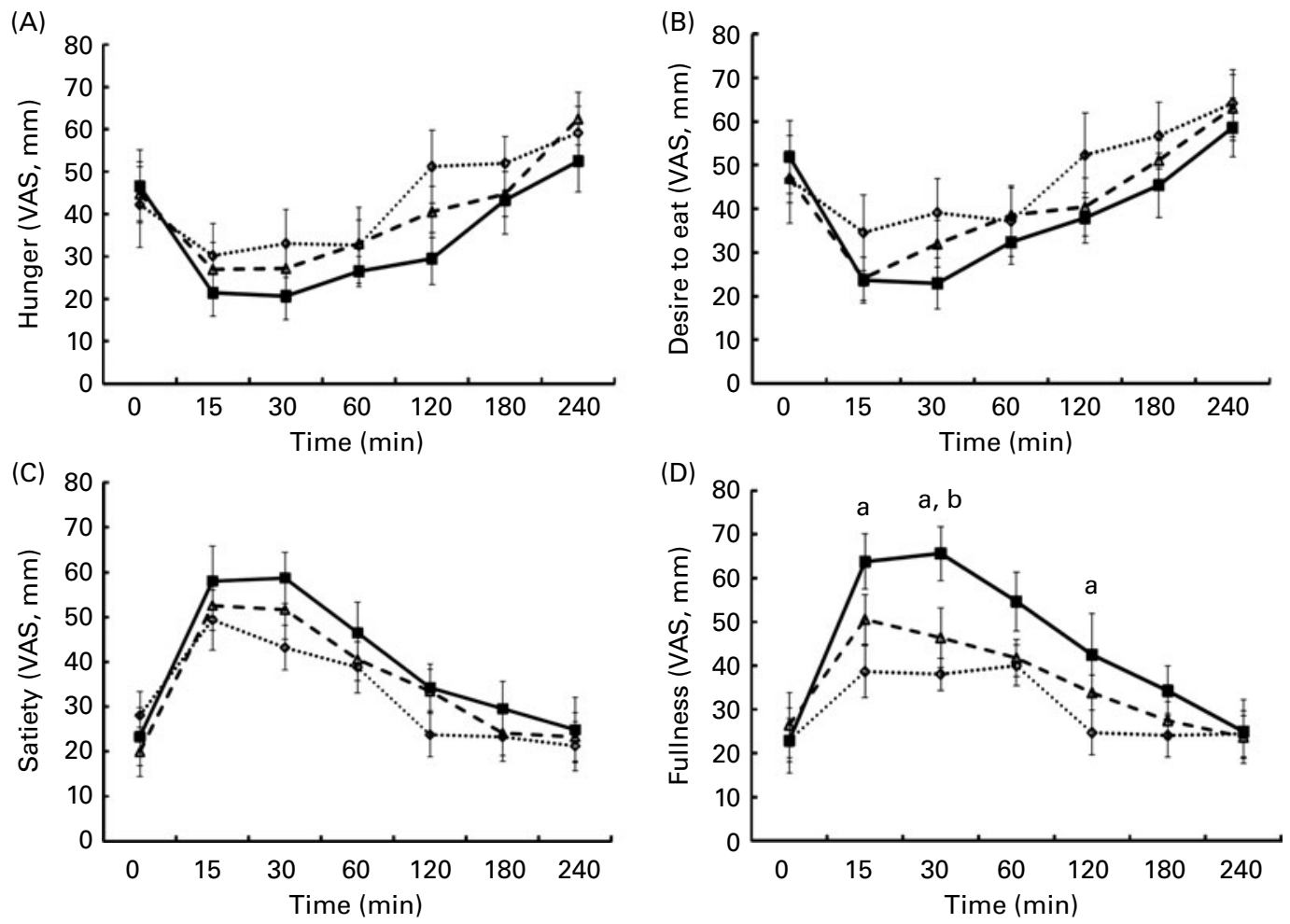

Fig. 3. Changes in the feeling of (A) hunger, (B) desire to eat, (C) satiety and (D) fullness during the 240 min postprandial period in young men consuming casein (Cas, $-\Delta-)$, transglutaminase-treated Cas (Cas-TG, $-\square-)$ or whey protein $(\mathrm{Wh}, . . \diamond . \cdot)$ test products. Values are means, with their standard errors $(n 8$; linear mixed-effects modelling with Bonferroni correction). ${ }^{\mathrm{a}, \mathrm{b}}$ Mean values with unlike letters were significantly different between Cas-TG and Wh and between Cas-TG and $\mathrm{Cas} / \mathrm{Wh}(P<0.05)$. VAS, visual analogue scale.

\section{Discussion}

In the present study, we found that the structure of three milk protein-based test foods affected postprandial glucose and insulin responses, GI hormone release and appetite ratings. Gelation of the test product by cross-linking Cas with TG resulted in attenuated postprandial glucose and insulin responses and CCK release and accentuated ratings of fullness.

Both the macro- and microstructure of food are potent modulators of postprandial physiology, affecting GE, digestion and absorption of nutrients with subsequent reflections in glucose and insulin responses, concomitant GI peptide secretion and appetite ${ }^{(9-12,18)}$

An increase in the viscosity or firmness of a food delays GE rate, and GE rate as well as post-ingestive hydrolysis affects postprandial glucose, insulin and GI peptide responses $^{(11,12,31,32)}$. The present results did thus support our hypothesis that firm food structure enhances satiety and attenuates postprandial metabolic responses. To our knowledge, the present study is the first one to demonstrate the effects of food texture and structure modification by enzymatic cross-linking on postprandial responses.

The release in insulin showed a marked increase after the ingestion of all protein products, but was attenuated after the consumption of Cas-TG. The fact that dietary protein stimulates postprandial insulin secretion is well documented ${ }^{(33,34)}$. The type and form (intact $v$. hydrolysate) of protein affects insulin release ${ }^{(33-36)}$. The insulin response did not differ between Cas and Wh in the present study, which is in contrast to some previous findings conducted with protein-rich test products suggesting that Wh would be more insulinotropic than intact Cas or glucose (34-36) $^{(2)}$ The reason for the comparable insulin responses between Wh and Cas in the present study is unknown and needs further clarification. Instead, an explanation for the different insulinotropic responses between Cas-TG and Cas/Wh in the present study might be the physical form of the test products. The liquid Wh and the viscous Cas were digested and absorbed more rapidly than the solid cross-linked Cas gel, which resulted most probably in a more pronounced AA response and, concomitantly, more enhanced insulin responses.

In the present study, the smaller decrease in postprandial glucose after the consumption of Cas-TG than after the consumption of Cas or Wh probably reflects the attenuated release of insulin following Cas-TG. The present glucose results are comparable with those of previous studies, also showing a slight decrease in postprandial glucose responses after protein drinks $^{(33,37,38)}$. Several previous studies have investigated the effects of various dietary proteins combined with carbohydrates or in mixed meals on postprandial glucose and insulin responses ${ }^{(33,34,36,39-41)}$, but studies comparing the postprandial effects of different protein types as such are sparse. The results suggest that protein ingestion alone may result in a small decrease in postprandial glucose both in healthy individuals $^{(33,37,38)}$ and in patients with type 2 diabetes $^{(42)}$ 
Postprandial blood glucose and subsequent insulin concentrations are largely determined by the rate at which nutrients are delivered to the proximal small intestine ${ }^{(43,44)}$. Since glucose and insulin responses were attenuated after the consumption of the Cas-TG test product, the present results suggest that GE may have been delayed after the consumption of Cas-TG. This is supported by previous studies showing that GE rate affects the magnitude and timing of postprandial blood glucose and insulin concentrations ${ }^{(43)}$. Moreover, protein type and food texture and structure have been shown to influence GE rate so that GE is slowed down after the consumption of Cas protein $(v$. Wh) and foods with solid texture ${ }^{(11,45)}$. We did not measure GE via our stable isotope technique available, because of the obvious differences in structure and thus the need for different tracers, which would not have been comparable.

Although data on milk proteins are still rather limited, dietary protein also affects the release of the GI-originating peptides, especially CCK, but also GLP-1 and PYY ${ }^{(5)}$. We observed a trend in postprandial GLP-1 responses, indicating that the test product with Wh and Cas stimulated GLP-1 secretion more than Cas-TG in the beginning of the study period. As would be expected, the trend was in the same direction as the postprandial responses of insulin. Because the difference in GLP-1 release between Cas-TG and CAS/ Wh was not quite statistically significant, GLP-1 does not solely explain the difference in postprandial insulin concentrations. The postprandial release of GLP-1 has been shown to be directly related both to the quality and quantity of dietary protein ${ }^{(8)}$. Previously, Wh has been reported to be a more potent stimulator for GLP-1 secretion than Cas, possibly because Wh may inhibit dipeptidyl peptidase IV, the enzyme responsible for the degradation of GLP-1 ${ }^{(46)}$. We found no significant difference in GLP-1 release between Wh and Cas, but, overall, the present results suggest that meal structure is more important than the type of protein on these GI hormone responses.

Dietary fat and protein have been shown to be the main stimulants for the CCK release ${ }^{(47)}$. In addition, the effects of Cas and Wh on the postprandial CCK release might also differ $^{(7)}$, or remain unchanged ${ }^{(48)}$, with comparable CCK responses after the consumption of liquid Cas and Wh test products. In the present study, the CCK response was more enhanced after the consumption of Cas and Wh than after the consumption of Cas-TG, indicating more rapid and pronounced digestion and subsequent stimulation of CCK producing I-cells after the consumption of Cas and Wh than after the consumption of Cas-TG.

We did not detect any marked postprandial PYY increase after the consumption of any of the protein-based test products nor were significant differences observed in PYY responses among the products. Previously, dietary protein in mixed meals has been shown to stimulate the postprandial secretion of $\mathrm{PYY}^{(49)}$, but results are still conflicting ${ }^{(50,51)}$ and studies utilising test products based exclusively on protein are very limited. Earlier studies have suggested that PYY is released in proportion to the energy content and macronutrient composition of the test meals ${ }^{(52,53)}$, indicating that the larger the energy and dietary fat content of the meal is, the more PYY is released. Thus, test products containing only protein, together with low and equal energy content, may explain partly the PYY results observed in the present study.

Fullness was significantly greater after the consumption of Cas-TG than after the consumption of Cas and Wh, which is in line with previous findings of greater satiety or fullness after the consumption of solid $v$. liquid foods ${ }^{(16,17,54)}$. In contrast, we did not observe any difference in postprandial satiety between liquid Cas and Wh. Some previous studies have suggested that Wh promotes greater satiety than Cas. The authors speculated that Wh is more soluble in the stomach, with faster GE and digestion rate and a more rapid postabsorptive AA response and more pronounced hormone secretion than after the consumption of $\mathrm{Cas}^{(6-8)}$. The reason for this discrepancy might be due to the high protein content of the test products of the present study, which probably induced postprandial AA concentrations high enough to abolish differences between Wh and Cas in postprandial hormone responses and feelings of satiety ${ }^{(8)}$.

Modification of the physico-chemical properties of foods can be used to affect postprandial GI function, metabolism and appetite. The difficulty in investigating the effects of food structure and texture on postprandial responses lies often in preparing of the test products, which would differ in these properties without changing the nutritional composition. In the present study, this was enabled by the utilisation of the cross-linking enzyme TG. As far as we are aware, this is the first human study in healthy individuals to compare the postprandial effects of two Cas-based model foods of similar composition and $\mathrm{pH}$, but of clearly differing texture and structure.

In conclusion, the present results suggest that increasing the firmness of dairy proteinaceous food is more effective in modulating the postprandial responses than the type of protein. Modification of protein-based food structure could thus offer a tool for optimising the postprandial glucose and insulin concentrations and influencing postprandial fullness.

\section{Acknowledgements}

We would like to express our sincere acknowledgments to Tuula Taskinen and Meeri Kröger for their excellent technical and laboratory assistance throughout the study. We gratefully acknowledge Maritta Siloaho, who provided the expert assistance with biochemical assays and analysis. The present study was supported by the Academy of Finland, The Finnish Graduate School on Applied Bioscience: Bioengineering, Food \& Nutrition, Environment and Kuopio University Hospital. K. R. J., L. J. K., M. E. L., K. S. P., D. E. L., H. M. M., L. K. N. and K.-H. H designed the research; K. R. J., E. V., T. K., A. J.-A. and K.-H. H. conducted the research; M. E. L. provided the protocol for preparing the test products; all authors contributed to the writing of the manuscript. All authors read and approved the final manuscript. None of the authors has conflicts of interest. 


\section{References}

1. Latner JD \& Schwartz M (1999) The effects of a highcarbohydrate, high-protein or balanced lunch upon later food intake and hunger ratings. Appetite 33, 119-128.

2. Halton TL \& Hu FB (2004) The effects of high protein diets on thermogenesis, satiety and weight loss: a critical review. J Am Coll Nutr 23, 373-385.

3. Astrup A (2005) The satiating power of protein - a key to obesity prevention? Am J Clin Nutr 82, 1-2.

4. Veldhorst MAB, Smeets AJPG, Soenen S, et al. (2008) Proteininduced satiety: effects and mechanisms of different proteins. Physiol Behav 94, 300-307.

5. Karhunen LJ, Juvonen KR, Huotari A, et al. (2008) Effect of protein, fat, carbohydrate and fibre on gastrointestinal peptide release in humans. Regul Pept 149, 70-78.

6. Boirie Y, Dangin M, Gachon P, et al. (1997) Slow and fast dietary proteins differently modulate postprandial protein accretion. Proc Natl Acad Sci USA 94, 14930-14935.

7. Hall WL, Millward DJ, Long SJ, et al. (2003) Casein and whey exert different effects on plasma amino acid profiles, gastrointestinal hormone secretion and appetite. Br J Nutr 89, 239-248.

8. Veldhorst MAB, Nieuwenhuizen AG, Hochstenbach-Waelen A, et al. (2009) Dose-dependent satiating effect of whey relative to casein or soy. Physiol Behav 96, 675-682.

9. Juntunen KS, Niskanen LK, Liukkonen KH, et al. (2002) Postprandial glucose, insulin, and incretin responses to grain products in healthy subjects. Am J Clin Nutr $\mathbf{7 5}$, 254-262.

10. Marciani L, Wickham M, Singh G, et al. (2007) Enhancement of intragastric acid stability of a fat emulsion meal delays gastric emptying and increases cholecystokinin release and gallbladder contraction. Am J Physiol Gastrointest Liver Physiol 292, G1607-G1613.

11. Kong F \& Singh RP (2008) Disintegration of solid foods in human stomach. J Food Sci 73, R67-R80.

12. Juvonen KR, Purhonen A-K, Salmenkallio-Marttila M, et al. (2009) Viscosity of oat bran enriched beverages influences gastrointestinal hormonal responses in healthy humans. J Nutr 139, 461-466.

13. Kristensen $M \&$ Jensen MG (2011) Dietary fibres in the regulation of appetite and food intake. Importance of viscosity. Appetite 56, 65-70.

14. Santangelo A, Peracchi M, Conte D, et al. (1998) Physical state of meal affects gastric emptying, cholecystokinin release and satiety. Br J Nutr $\mathbf{8 0}, 521-527$.

15. Tieken SM, Leidy HJ, Stull AJ, et al. (2007) Effects of solid versus liquid meal-replacement products of similar energy content on hunger, satiety, and appetite-regulating hormones in older adults. Horm Metab Res 39, 389-394.

16. Mattes RD \& Rothacker D (2001) Beverage viscosity is inversely related to postprandial hunger in humans. Physiol Behav 74, 551-557.

17. Akhavan T, Luhovyy BL \& Anderson GH (2011) Effect of drinking compared with eating sugars or whey protein on short-term appetite and food intake. Int J Obes (Lond) 35, 562-569.

18. Martens MJ, Lemmens SG, Born JM, et al. (2011) A solid high-protein meal evokes stronger hunger suppression than a liquefied high-protein meal. Obesity (Silver Spring) 19, 522-527.

19. Zijlstra N, Mars M, de Wijk RA, et al. (2009) Effect of viscosity on appetite and gastro-intestinal hormones. Physiol Behav 97, 68-75.
20. Zijlstra N, de Wijk RA, Mars M, et al. (2009) Effect of bite size and oral processing time of a semisolid food on satiation. Am J Clin Nutr 90, 269-275.

21. de Wijk RA, Zijlstra N, Mars M, et al. (2008) The effects of food viscosity on bite size, bite effort and food intake. Physiol Behav 95, 527-532.

22. Karl JP, Young AJ \& Montain SJ (2011) Eating rate during a fixed-portion meal does not affect postprandial appetite and gut peptides or energy intake during a subsequent meal. Physiol Behav 102, 524-531.

23. Almiron-Roig E, Chen Y \& Drewnowski A (2003) Liquid calories and the failure of satiety: how good is the evidence? Obes Rev 4, 201-212.

24. Gerrard JA (2002) Protein-protein crosslinking in food: methods, consequences, applications. Trends Food Sci Technol 13, 391-399.

25. Lantto R (2007) Protein cross-linking with oxidative enzymes and transglutaminase: effects in meat protein systems. PhD Thesis, University of Helsinki.

26. Feeney RE \& Whitaker JR (1988) Importance of cross-linking reactions in proteins. Adv Cereal Sci Technol 9, 21-46.

27. Jaros D, Partschefeld C, Henle T, et al. (2006) Transglutaminase in dairy products: chemistry, physics and applications. J Texture Studies 37, 113-155.

28. Lille M, Ercili-Cura D, Partanen R, et al. (2009) Crosslinking enzymes as tool for structure engineering of milk protein based foods. In Proceedings of the 5th International Symposium on Food Rheology and Structure, pp. 396-399. Zurich, Switzerland: ETH Swiss Federal Institute of Technology Zurich.

29. Seguro K, Kumazawa Y, Kuraishi C, et al. (1996) The epsilon-(gamma-glutamyl)lysine moiety in crosslinked casein is an available source of lysine for rats. J Nutr 126, 2557-2562.

30. Stubbs RJ, Hughes DA, Johnstone AM, et al. (2000) The use of visual analogue scales to assess motivation to eat in human subjects: a review of their reliability and validity with an evaluation of new hand-held computerized systems for temporal tracking of appetite ratings. Br J Nutr $\mathbf{8 4}$, 405-415.

31. Marciani L, Gowland PA, Spiller RC, et al. (2001) Effect of meal viscosity and nutrients on satiety, intragastric dilution, and emptying assessed by MRI. Am J Physiol Gastrointest Liver Physiol 280, G1227-G1233.

32. Karhunen LJ, Juvonen KR, Flander SM, et al. (2010) Psyllium fiber-enriched meal strongly attenuates postprandial gastrointestinal peptide release in healthy young adults. $J$ Nutr 140, 737-744

33. Karamanlis A, Chaikomin R, Doran S, et al. (2007) Effects of protein on glycemic and incretin responses and gastric emptying after oral glucose in healthy subjects. Am J Clin Nutr 86, 1364-1368.

34. Nilsson M, Stenberg M, Frid AH, et al. (2004) Glycemia and insulinemia in healthy subjects after lactose equivalent meals of milk and other food proteins: the role of plasma amino acids and incretins. Am J Clin Nutr 80, 1246-1253.

35. van Loon LJ, Saris WH, Verhagen H, et al. (2000) Plasma insulin responses after ingestion of different amino acid or protein mixtures with carbohydrate. Am J Clin Nutr 72, 96-105.

36. Nilsson M, Holst JJ \& Björck IM (2007) Metabolic effects of amino acid mixtures and whey protein in healthy subjects: studies using glucose-equivalent drinks. Am J Clin Nutr $\mathbf{8 5}$, 996-1004.

37. Claessens M, Saris WIM \& van Baak MA (2008) Glucagon and insulin responses after ingestion of different amounts of intact and hydrolysed proteins. Br J Nutr 100, 61-69. 
38. Pal S \& Ellis V (2010) The acute effects of four protein meals on insulin, glucose, appetite and energy intake in lean men. Br J Nutr 104, 1241-1248.

39. Nuttall FQ \& Gannon MC (1991) Plasma glucose and insulin response to macronutrients in nondiabetic and NIDDM subjects. Diabetes Care 14, 824-838.

40. Bowen J, Noakes M \& Clifton PM (2006) Appetite regulatory hormone responses to various dietary proteins differ by body mass index status despite similar reductions in ad libitum energy intake. J Clin Endocrinol Metab 91, 2913-2919.

41. Lang V, Bellisle F, Oppert JM, et al. (1998) Satiating effect of proteins in healthy subjects: a comparison of egg albumin, casein, gelatin, soy protein, pea protein, and wheat gluten. Am J Clin Nutr 67, 1197-1204.

42. Gannon MC, Nuttall FQ, Neil BJ, et al. (1988) The insulin and glucose responses to meals of glucose plus various proteins in type II diabetic subjects. Metabolism 37, 1081-1088.

43. Rayner CK, Samsom M, Jones KL, et al. (2001) Relationships of upper gastrointestinal motor and sensory function with glycemic control. Diabetes Care 24, 371-381.

44. Ma J, Rayner CK, Jones KL, et al. (2009) Insulin secretion in healthy subjects and patients with Type 2 diabetes - role of the gastrointestinal tract. Best Pract Res Clin Endocrinol Metab 23, 413-424.

45. Mahé S, Roos N, Benamouzig R, et al. (1996) Gastrojejunal kinetics and the digestion of [15N]beta-lactoglobulin and casein in humans: the influence of the nature and quantity of the protein. Am J Clin Nutr 63, 546-552.

46. Gunnarsson PT, Winzell MS, Deacon CF, et al. (2006) Glucose-induced incretin hormone release and inactivation are differently modulated by oral fat and protein in mice. Endocrinology 147, 3173-3180.

47. Liddle RA, Goldfine ID, Rosen MS, et al. (1985) Cholecystokinin bioactivity in human plasma. Molecular forms, responses to feeding, and relationship to gallbladder contraction. J Clin Invest 75, 1144-1152.

48. Bowen J, Noakes M, Trenerry C, et al. (2006) Energy intake, ghrelin, and cholecystokinin after different carbohydrate and protein preloads in overweight men. J Clin Endocrinol Metab 91, 1477-1483.

49. Batterham RL, Heffron H, Kapoor S, et al. (2006) Critical role of peptide $\mathrm{YY}$ in protein-mediated satiation and bodyweight regulation. Cell Metab 4, 223-233.

50. Helou N, Obeid O, Azar ST, et al. (2008) Variation of postprandial $\mathrm{PYY}_{3-36}$ response following ingestion of differing macronutrient meals in obese females. Ann Nutr Metab 52, 188-195.

51. Essah PA, Levy JR, Sistrun SN, et al. (2007) Effect of macronutrient composition on postprandial peptide YY levels. J Clin Endocrinol Metab 92, 4052-4055.

52. Adrian TE, Ferri GL, Bacarese-Hamilton AJ, et al. (1985) Human distribution and release of a putative new gut hormone, peptide YY. Gastroenterology 89, 1070-1077.

53. Degen L, Oesch S, Casanova M, et al. (2005) Effect of peptide $\mathrm{YY}_{3-36}$ on food intake in humans. Gastroenterology 129, 1430-1436.

54. Hulshof T, De Graaf C \& Weststrate JA (1993) The effects of preloads varying in physical state and fat content on satiety and energy intake. Appetite 21, 273-286. 